\title{
Life Satisfaction, Positive Youth Development, and Problem Behaviour Among Chinese Adolescents in Hong Kong
}

\author{
Rachel C. F. Sun • Daniel T. L. Shek
}

Accepted: 13 May 2009/Published online: 10 October 2009

(C) The Author(s) 2009. This article is published with open access at Springerlink.com

\begin{abstract}
This paper examines the relationships among life satisfaction, positive youth development, and problem behaviour. A total of 7,975 Secondary One students $(4,169$ boys and 3,387 girls; with most aged 12) of Chinese ethnicity recruited from 48 schools responded to validated measures of life satisfaction, positive youth development and problem behaviour. While life satisfaction was positively correlated with different measures of positive youth development, these measures were negatively correlated with measures of substance abuse, delinquency and intention to engage in problem behaviour. Based on a series of structural equation models, a non-recursive model was found to best fit the data, which suggests that adolescents having higher levels of positive youth development are more satisfied with life and have fewer problem behaviour, with life satisfaction and problem behaviour negatively reinforcing each other.
\end{abstract}

Keywords Adolescents · Positive youth development · Life satisfaction · Problem behaviour

\section{Introduction}

In the past two decades, increasing attention has been paid to positive youth development and adolescent subjective well-being (SWB). Park (2004) pointed out that "SWB serves not only as a key indicator of positive development but also as a broad enabling factor that promotes and maintains optimal mental health" (p. 27). Similarly, based on their work in primary prevention, Meyers and Meyers (2003) proposed that positive youth development could be enhanced by strengthening one's subjective well-being, competence and social

R. C. F. Sun

Department of Social Work, The Chinese University of Hong Kong, Shatin, New Territories, Hong Kong

D. T. L. Shek $(\bowtie)$

Department of Applied Social Sciences, The Hong Kong Polytechnic University, Hung Hom,

Kowloon, Hong Kong

e-mail: Daniel.shek@polyu.edu.hk 
support, and at the same time mitigating poor individual predisposition, stress and exploitation. In short, researchers have argued that subjective well-being and its cognitive components (such as life satisfaction, Diener et al. 1999) are factors enabling positive development (Child Trends 2003; Damon 2004). However, before assuming that life satisfaction is an indicator of positive youth development, the operational definition of positive youth development must first be outlined.

In their review of positive youth development programs in North America, Catalano et al. (2004) pointed out that positive youth development comprises fifteen inter-related constructs-bonding, social competence, emotional competence, cognitive competence, behavioural competence, moral competence, self-efficacy, prosocial norms, resilience, self-determination, spirituality, clear and positive identity, beliefs in the future, prosocial involvement, and recognition of positive behaviour (for definitions of these constructs, see Table 1). Among these positive youth development constructs, many were found to associate with life satisfaction: Paxton et al. (2006) showed that bonding to adults and owning meaningful social roles were closely related to adolescent life satisfaction; Stein and Newcomb (1999) reported that intimate relationships formed in early adulthood contributed to life satisfaction in later adulthood; Ciarrochi et al. (2003) found that social and emotional competencies were significant predictors of life satisfaction. Academic and social self-efficacy (Vecchio et al. 2007), prosocial motivation and behaviour (Caprara and Steca 2005; Gebauer et al. 2008), spirituality and religiosity (Laudet and White 2008; Zullig et al. 2006), as well as mastery and ethnic identity (Sam 1998) were also found to be significant predictors of life satisfaction. In sum, using Catalano et al.'s (2004) definition of positive youth development, the above studies demonstrate that positive youth development predicts life satisfaction. Unfortunately, the possible influence of life satisfaction on positive youth development was not examined in these studies.

In addition, positive youth development was found to associate with positive behaviour but negatively relate to problem behaviour, such as substance abuse and delinquency. According to Catalano et al.'s review (2004) on 25 well-evaluated positive youth development programs, about $76 \%$ increased adolescents' positive behaviour and about $96 \%$ reduced problem behaviour. Since the fifteen positive youth development constructs proposed by Catalano et al. (2004) refer to how individuals' internal and external resources help them deal with challenges, they can be regarded as protective factors alleviating the development of problem behaviour, as proposed in the resilience literature on risk and protective factors (e.g., Jessor et al. 2003). This concept and related theories of protective factors suggest a predictive relationship of positive youth development to problem behaviour.

Empirically speaking, the findings on the predictive effects of positive youth development on life satisfaction and problem behaviour were quite piecemeal because not all the fifteen constructs were examined simultaneously in a single study. Moreover, although integrative models were tested by using structural-equation modelling or hierarchical regressions to demonstrate the predictive effect of positive youth development on problem behaviour (Jessor et al. 2003; Lent et al. 2005), these cross-sectional studies did not examine the reverse predictive effect of problem behaviour on positive youth development. This research gap can be filled by testing the predictive relationship of positive youth development to life satisfaction and problem behaviour, as well as possible reverse or even bidirectional relationships.

Studies have shown that life satisfaction is negatively associated with adolescent problem behaviour: sexual risk-taking behaviours (Valois et al. 2002); substance abuse, such as cigarette smoking, chewing tobacco, marijuana, cocaine, regular alcohol use, binge drinking (Desousa et al. 2008; Piko et al. 2005; Zullig et al. 2001); and violence and aggression, such as carrying a gun or weapon, physical fighting, stealing or damaging 
Table 1 Definitions of the theoretical constructs, reliability statistics (mean inter-item correlation coefficients and coefficient alphas), and mean and standard deviations

\begin{tabular}{|c|c|c|c|c|}
\hline Theoretical construct & Definition & $\begin{array}{l}\text { Mean } \\
\text { inter-item } \\
\text { correlation }\end{array}$ & Alpha & Mean (SD) \\
\hline $\begin{array}{l}\text { Life satisfaction (LS): } \\
5 \text { items }\end{array}$ & Global judgment of one's quality of life. & .49 & .81 & $4.12(1.04)$ \\
\hline Bonding (BO): 6 items & $\begin{array}{l}\text { Development of positive relationship with } \\
\text { healthy adults and positive peers. }\end{array}$ & .45 & .83 & $4.82(.79)$ \\
\hline Resilience (RE): 6 items & $\begin{array}{l}\text { Capacity for adapting to changes and stressful } \\
\text { events in healthy and adaptive ways. }\end{array}$ & .44 & .82 & $4.70(.81)$ \\
\hline $\begin{array}{l}\text { Social competence (SC): } \\
7 \text { items }\end{array}$ & $\begin{array}{l}\text { Interpersonal skills such as communication and } \\
\text { conflict resolution skills. }\end{array}$ & .42 & .83 & $4.63(.77)$ \\
\hline $\begin{array}{l}\text { Recognition for positive } \\
\text { behaviour (RB): } \\
4 \text { items }\end{array}$ & $\begin{array}{l}\text { Systems for rewarding, recognizing or } \\
\text { reinforcing positive behaviour. }\end{array}$ & .44 & .76 & $4.50(.88)$ \\
\hline $\begin{array}{l}\text { Emotional competence } \\
\text { (EC): } 6 \text { items }\end{array}$ & $\begin{array}{l}\text { Skills to recognize feelings in oneself and } \\
\text { others and emotional self-management } \\
\text { strategies. }\end{array}$ & .44 & .83 & $4.25(.90)$ \\
\hline $\begin{array}{l}\text { Cognitive competence } \\
\text { (CC): } 6 \text { items }\end{array}$ & $\begin{array}{l}\text { Cognitive skills such as problem solving and } \\
\text { goal setting. }\end{array}$ & .47 & .84 & $4.46(.84)$ \\
\hline $\begin{array}{l}\text { Behavioural competence } \\
\text { (BC): modified } 5 \text { items }\end{array}$ & $\begin{array}{l}\text { Behavioural skills such as taking action skills } \\
\text { and provision of reinforcement for effective } \\
\text { behaviour choices and action pattern. }\end{array}$ & .38 & .76 & $4.72(.77)$ \\
\hline $\begin{array}{l}\text { Moral competence } \\
\text { (MC): } 6 \text { items }\end{array}$ & $\begin{array}{l}\text { Ability to differentiate right and wrong and } \\
\text { respect for rules and standards as well as } \\
\text { social justice. }\end{array}$ & .37 & .78 & $4.47(.81)$ \\
\hline $\begin{array}{l}\text { Self-determination }(\mathrm{SD}) \text { : } \\
5 \text { items }\end{array}$ & $\begin{array}{l}\text { Sense of autonomy, independent thinking, or } \\
\text { self-advocacy. }\end{array}$ & .40 & .76 & $4.74(.77)$ \\
\hline $\begin{array}{l}\text { Self-efficacy (SE): } \\
\text { modified } 2 \text { items }\end{array}$ & Skills for coping and mastery. & .34 & .50 & $4.33(1.03)$ \\
\hline $\begin{array}{l}\text { Clear and positive } \\
\text { identity (ID): } 7 \text { items }\end{array}$ & $\begin{array}{l}\text { Development of healthy identity formation and } \\
\text { achievement. }\end{array}$ & .43 & .84 & $4.19(.89)$ \\
\hline $\begin{array}{l}\text { Beliefs in the future } \\
(\mathrm{BF}) \text { : modified } 3 \text { items }\end{array}$ & $\begin{array}{l}\text { Ability to develop future potential goals, } \\
\text { choices, or options. }\end{array}$ & 61 & .82 & $4.45(1.09)$ \\
\hline $\begin{array}{l}\text { Prosocial involvement } \\
\text { (PI): } 5 \text { items }\end{array}$ & $\begin{array}{l}\text { Activities and events to make positive } \\
\text { contribution to groups. }\end{array}$ & .49 & .83 & $4.54(.91)$ \\
\hline $\begin{array}{l}\text { Prosocial norms }(\mathrm{PN}) \text { : } \\
5 \text { items }\end{array}$ & $\begin{array}{l}\text { Development of clear and explicit standards } \\
\text { for prosocial engagement. }\end{array}$ & .40 & .77 & $4.68(.86)$ \\
\hline Spirituality (SP): 7 items & $\begin{array}{l}\text { Sense of purpose and meaning in life, hope, } \\
\text { or beliefs in a higher power. }\end{array}$ & .51 & .88 & $5.24(1.21)$ \\
\hline $\begin{array}{l}\text { Positive youth } \\
\text { development (PYD): } \\
80 \text { items }\end{array}$ & $\begin{array}{l}\text { Positive adolescent development defined in } \\
\text { terms of healthy, holistic, and valuable } \\
\text { developmental attributes, assets, and } \\
\text { potentials. }\end{array}$ & .54 & .94 & $4.58(.67)$ \\
\hline $\begin{array}{l}\text { Substance abuse (SA): } \\
8 \text { items }\end{array}$ & Consumption of alcohol and drugs. & .51 & .88 & NA \\
\hline $\begin{array}{l}\text { Delinquency (DE): } \\
12 \text { items }\end{array}$ & Engagement in antisocial behaviour. & .56 & .76 & NA \\
\hline $\begin{array}{l}\text { Intention to engage in } \\
\text { problem behaviour } \\
\text { (BI): } 5 \text { items }\end{array}$ & Purpose of involving in high-risk behaviour. & .47 & .76 & NA \\
\hline
\end{tabular}


Table 1 continued

\begin{tabular}{llll}
\hline Theoretical construct & Definition & $\begin{array}{l}\text { Mean } \\
\text { inter-item } \\
\text { correlation }\end{array}$ & Alpha Mean (SD) \\
\hline $\begin{array}{l}\text { Problem behaviour (PB): } \\
25 \text { items }\end{array}$ & $\begin{array}{l}\text { Problem behaviour defined in terms of } \\
\text { substance abuse, delinquency and intention to } \\
\text { engage in problem behaviour. }\end{array}$ & .53 & NA \\
\hline
\end{tabular}

property at school, and drinking and driving (MacDonald et al. 2005; Valois et al. 2001). In addition, life satisfaction was found to act as a predictor of suicide ideation (Heisel and Flett 2004). Theoretically, adolescents who were dissatisfied with life might have had poor strategies to cope with life stress and thus engaged in sexual behaviours, substance abuse and even delinquency and suicide attempts (Kim and Kim 2008). On the other hand, longitudinal research also pointed out that heavy substance or tobacco use in adolescence was a precursor of lower levels of life satisfaction, relationship satisfaction, and physical and mental health in adulthood (Fergusson and Boden 2008; Georgiades and Boyle 2007). Since research findings on the relationships between life satisfaction and problem behaviour are equivocal, investigation of the predictive contribution of life satisfaction to problem behaviour, as well as that of problem behaviour to life satisfaction, and even their bidirectional relationship, is needed.

The picture of the relationships among positive youth development, life satisfaction and adolescent problem behaviour becomes more complicated when researchers treat life satisfaction as a mediator. While most of the existing studies treated life satisfaction either as an outcome variable (e.g., Gebauer et al. 2008; Laudet and White 2008; Vecchio et al. 2007) or as a predictor (e.g., Heisel and Flett 2004; Swami et al. 2007), several studies examined the mediating influence of life satisfaction on problem behaviour. For instance, McKnight et al. (2002) found that life satisfaction partially mediated the relationship between stressful life events and adolescent problem behaviour. Suldo and Huebner (2004) also demonstrated that life satisfaction had not only a partial mediating effect between authoritative parenting and adolescent problem behaviour, but also a full mediating effect between parental involvement and adolescent problem behaviour. Based on these findings, further examination of the mediating role of life satisfaction to problem behaviour is needed.

In the Hong Kong context, studies on life satisfaction among adolescents have commonly used the correlational method (e.g., Shek 1998a, 1998b; Shek et al. 2006a). A few used multivariate statistical analyses, like multiple regression (Chan 2007; Chang et al. 2003) and structural equation modelling (Leung and Zhang 2000), but predictors were limited to family factors (such as parent-adolescent relationship, parental warmth and emotional detachment) and intrapersonal factors (such as self-concept and perfectionism). No study has been conducted in Hong Kong to examine positive youth development involving the fifteen constructs developed by Catalano et al. (2004) as predictors of life satisfaction, though there is an emerging body of positive youth development literature.

From a Hong Kong perspective, there are four reasons to examine the relationships among life satisfaction, positive youth development and adolescent problem behaviour. First, since harmonious relationships, moral values, prosocial norms and behaviours are highly valued in Chinese culture, it is interesting to study how these factors are related to adolescent life satisfaction and problem behaviour. Second, despite problem behaviour being less common among Chinese adolescents than among their Western counterparts 
(Jessor et al. 2003), there is a rising trend of adolescent developmental problems, such as abuse of psychotropic substances (Shek 2007), adolescent suicide (Sun and Hui 2007) and school violence (Wong 2004). Third, because of the addictive nature of problem behaviour, it is valuable to examine adolescents' intention of engaging in problem behaviour such as substance abuse and delinquency. Finally, while Western studies show that positive youth development predicts life satisfaction and problem behaviour (e.g., Catalano et al. 2004), relevant studies are almost non-existent in the Chinese contexts and it remains unknown whether isolated Western findings can be generalized to the Chinese culture.

Against this background, the main goal is to test the structural models of the predictive relationships among positive youth development, life satisfaction and problem behaviour. Theoretically, with structural equation modelling, a model could clearly delineate predictive relationships between the predictor and criterion variables. From the literature review, it is hypothesized that positive youth development is positively related with life satisfaction, and that both of them are negatively related with problem behaviour.

To answer the research question of whether there would be direct, indirect, mediating, reverse or bidirectional paths among the three variables, six hypothetical models were proposed with reference to the positive youth development theoretical framework (Catalano et al. 2004), empirical research findings, and logical deductions. First, with structural equation modelling, the possible partial or full mediation role of life satisfaction (Model 1 and Model 2) was tested. Second, due to the cross-sectional nature of the present data, a possible reverse predictive relationship (Model 3) was examined to further demonstrate the predictive directionality of the variables. Third, alternative bidirectional relationships among the variables based on logical reasoning were also tested (Models 4 and 5), though the bidirectional relationship between life satisfaction and problem behaviour (Model 6) was rather clearly shown by the previous studies. After model testing and comparison, the model with the most optimal fit indices would be considered.

- Model 1: It was hypothesized that positive youth development would have a positive effect on life satisfaction but a negative effect on problem behaviour, with life satisfaction partially mediating the impact of positive youth development on problem behaviour relationship. (i.e., partial mediation model)

- Model 2: It was hypothesized that positive youth development would have a positive effect on life satisfaction, and that life satisfaction would have a negative effect on problem behaviour. (i.e., full mediation model)

- Model 3: It was hypothesized that adolescent problem behaviour would have negative effects on positive youth development as well as life satisfaction, and that life satisfaction would have a positive effect on positive youth development. (i.e., reverse effect model)

- Model 4: It was hypothesized that positive youth development and life satisfaction would have a bidirectional relationship. Both positive youth development and life satisfaction would have negative effects on problem behaviour. (i.e., non-recursive model with a bidirectional path between exogenous and one endogenous variables)

- Model 5: It was hypothesized that positive youth development would have a bidirectional relationship on life satisfaction and a negative effect on problem behaviour. Also, life satisfaction and problem behaviour would have a bidirectional relationship. (i.e., non-recursive model with two bidirectional paths)

- Model 6: It was hypothesized that positive youth development would have a positive effect on life satisfaction and a negative effect on problem behaviour, with life satisfaction and problem behaviour having a bidirectional relationship. (i.e., nonrecursive model with a bidirectional path between two endogenous variables) 


\section{Method}

\subsection{Participants and Procedure}

Project Positive Adolescent Training through Holistic Social Programmes (P.A.T.H.S.) is a pioneering positive youth development program designed for junior secondary-school students in Hong Kong, with the aim of promoting holistic development among adolescents. In the first year of the Full Implementation Phase (the 2006-2007 school year), a total of 24 experimental schools ( $n=4,121$ students) and 24 control schools $(n=3,854$ students) were randomly selected to join a longitudinal study. In Wave 1 of the data collection, all the Secondary One students $(N=7,975)$ completed the objective outcome questionnaire prior to program implementation. Of these, $4,169(52.3 \%)$ were boys and $3,387(42.5 \%)$ were girls, with the remaining $5.2 \%$ not reporting their gender. A majority of the students reported their age as $12(60.5 \%), 13(14.9 \%)$ or $11(12.5 \%)$. Further details of the project can be seen in studies by Shek and Ma (2006) and Shek and Sun (2009).

Data were collected at the schools by trained research staff and/or school teachers with adequate advance briefings. Parental and school consent were obtained prior data collection. At the time of data collection, student consent was sought, the purpose of the study was mentioned, and the confidentiality of the data collected was repeatedly emphasized to all students. After giving instructions, adequate time was provided for all participants to respond to all scales in the questionnaires in a self-administration format. No students refused to complete the questionnaires.

\subsection{Instruments}

The study used an objective outcome evaluation questionnaire (Shek et al. 2006b) in Chinese, containing measures of positive youth development, life satisfaction, adolescent problem behaviour and demographic characteristics.

\subsubsection{Assessment of Positive Youth Development}

Positive youth development was measured by the modified Chinese Positive Youth Development Scale (Shek et al. 2008). A detailed description of the scale, as well as its items and psychometric properties, can be found in Shek et al.'s study (2007). The scale includes 15 subscales: bonding, social competence, emotional competence, cognitive competence, behavioural competence, moral competence, self-efficacy, prosocial norms, resilience, self-determination, spirituality, clear and positive identity, beliefs in the future, prosocial involvement, and recognition of positive behaviour (see Table 1). Except spirituality, which was measured by a seven-point rating scale, all categories had a six-point rating scale. Positive youth development was represented by these 15 indicators - a final score was obtained by averaging the items in each subscale.

\subsubsection{Assessment of Life Satisfaction}

Life satisfaction was measured by the five-item Life Satisfaction Scale on a 6-point rating scale (Diener et al. 1985), which assesses one's own global judgment of one's quality of life. The Chinese translation was found to have acceptable psychometric properties (Shek 2004). 


\subsubsection{Assessment of Problem Behaviour}

Problem behaviour was measured by three subscales. The first was an eight-item measure of substance abuse, examining via a seven-point rating scale the respondent's frequency of using alcohol, tobacco, ketamine, cannabis, cough mixture, organic solvent, pills, and narcotics. The second subscale is a 12-item measure of delinquency, examining via a seven-point rating scale the respondent's frequency of engaging in antisocial behaviour such as stealing, cheating, truancy, running away from home, damaging property, assault, having sexual relationship with others, gang fighting, speaking foul language, staying away from home without parental consent, strong-arming others, and breaking into residences. The third subscale uses a four-point rating scale and is a five-item measure of intention to engage in problem behaviour, including consuming alcohol, smoking, consuming illicit drugs, engaging in sexual behaviour, and gambling. These subscales were found to have acceptable construct validity (Shek 2004). Problem behaviour was represented by these three indicators, which were obtained by averaging the items in each subscale.

\subsection{Data Analyses}

The hypothetical models were tested by structural equation modelling (LISREL 8, linear structural relations; Jöreskog and Sörbom 1999). Since the present study was based on a community adolescent sample, it was predicted that the problem behaviour data would be positively skewed and kurtosic (i.e., not normally distributed). To tackle the issue of data non-normality, maximum likelihood (ML) in the latest version of LISREL 8.80 and PRELIS 2.54 was used to estimate the free parameters in the models. PRELIS 2.80 gives the estimations of polychoric covariance and asymptotic covariance matrices, which allow ML to provide the Satorra-Bentler scaled chi-squares in the LISREL 8.80 solutions for estimating the non-normal data. Evaluation of model fit was based on multiple criteria, including the theoretical meaningfulness of the model, absolute-fit indices (how well a model fits the data, without comparing to a baseline model), incremental fit measures (how much better the model fits than a baseline model) and model cross-validation (how the model can be replicated with an independent sample). Absolute fit indices include SatorraBentler scaled chi-square $\left(\chi^{2}\right)$, root mean square error of approximation (RMSEA), goodness-of-fit index (GFI), and standardized root mean residual (SRMR). Incremental fit measures include the non-normed fit index (NNFI) and the comparative fit index (CFI). For model cross-validation, the total sample was split randomly into two sub-samples for model exploration and validation, respectively, and a cross-validation index (CVI) was computed to indicate discrepancies among the sub-samples.

\section{Results}

Reliability analyses showed that all the scales and subscales except the self-efficacy subscale were highly reliable, i.e., they had alpha coefficients above .75 (Table 1). Results in Table 2 showed that the prevalence of problem behaviour was very low among Chinese early adolescents. More than $90 \%$ of the respondents reported that they had never smoked or abused drugs (other than drinking alcohol) in the previous 6 months. While about half of the respondents reported that they had cheated somebody and/or spoken foul language, a majority had never been involved in other kinds of delinquent behaviours, such as a sexual relationship in the previous 6 months. However, some respondents did intend to drink 


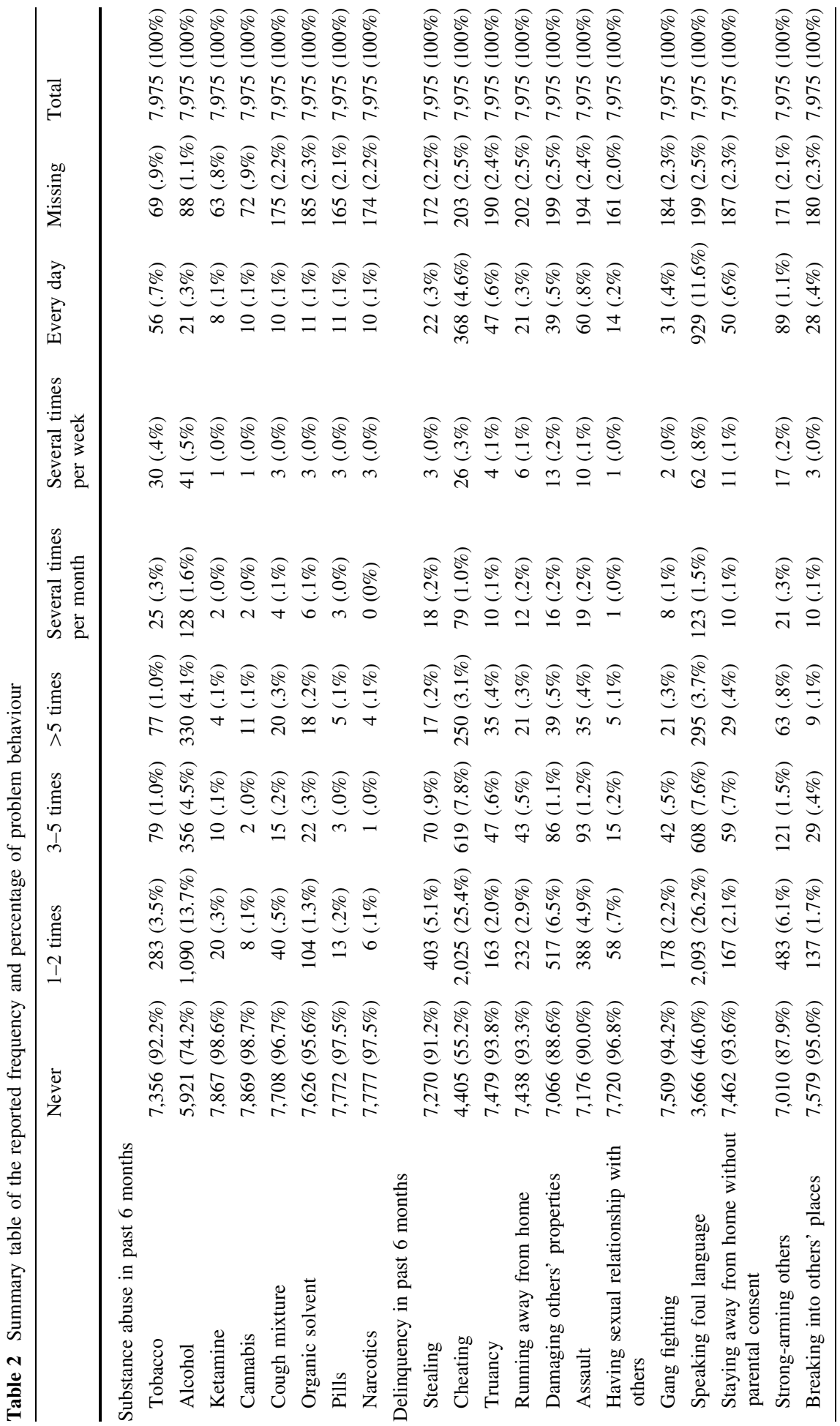




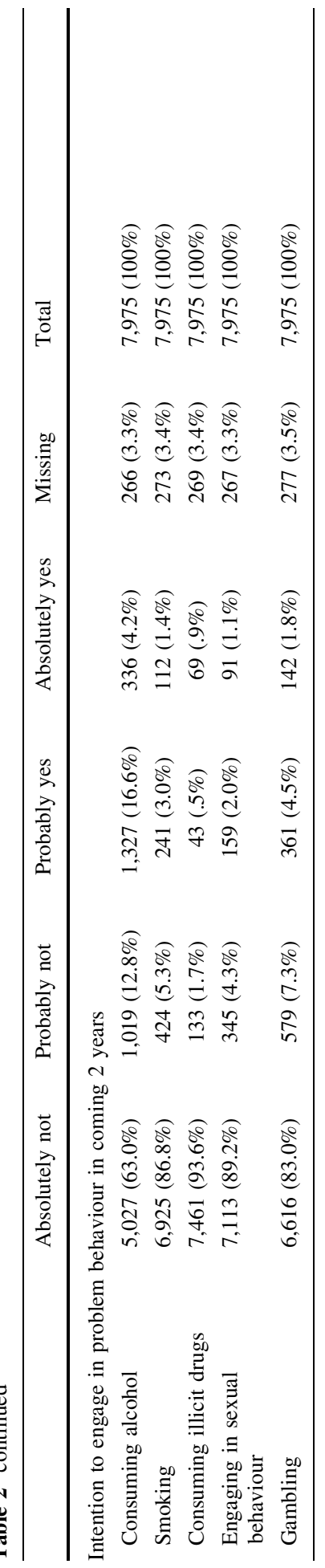


alcohol (20.8\%), gamble (6.3\%), smoke (4.4\%), have sex (3.1\%), and consume illicit drugs $(1.4 \%)$ in the subsequent 2 years.

As shown in Table 3, analyses based on Pearson correlation showed that all variables were correlated in the expected directions (with a two-tailed multistage Bonferroni correction). Life satisfaction was positively correlated with different measures of positive youth development and global positive youth development, while negatively correlated with substance abuse, delinquency, intention to engage in problem behaviour, and global problem behaviour.

As expected, variables were normally distributed, except the values of drug and delinquency of problem behaviour variables which showed positive skewness and kurtosis. In two-step modelling (Anderson and Gerbing 1988), the measurement models of the positive youth development, life satisfaction, and problem behaviour were tested first. Results showed that the fifteen-indicator positive youth development fit the data [SatorraBentler scaled $\chi^{2}(90, n=3,987)=1,580.48$; RMSEA $=0.06$; GFI $=0.89$; SRMR $=$ $0.041 ; \mathrm{NNFI}=0.99 ; \mathrm{CFI}=0.99 ; \mathrm{CVI}=0.95]$ and that the three-indicator problem behaviour had excellent fit indices [Satorra-Bentler scaled $\chi^{2}(0, n=3,987)=0$; $\mathrm{CVI}=0.02]$. The construct validity of both scales was supported. For the five-indicator life satisfaction, the goodness-of-fit indices indicated that the model did not fit well. Since item 5 had a relatively lower loading and measures a hypothetical situation which is different from the other items, item 5 was dropped. The modified four-indicator life satisfaction had a significant $\chi^{2}$-difference $\left(\Delta \chi^{2}=199.7, \Delta d f=3, p<0.01\right)$, and good fit [Satorra-Bentler scaled $\chi^{2} \quad(2, \quad n=3,987)=9.14 ; \quad$ RMSEA $=0.03 ; \quad$ GFI $=1.00$; $\mathrm{SRMR}=0.010 ; \mathrm{NNFI}=1.00 ; \mathrm{CFI}=1.00 ; \mathrm{CVI}=0.95]$, which indicated that the scale would be better represented by four items which measure life satisfaction in similar contexts.

To examine the structural model of quality of life, the proposed models were tested and compared. The one showing optimal fit was selected to represent the final model.

\subsection{Step (1): Testing Model 1}

As shown in Table 4, the fit indices of Model 1 were adequate [Satorra-Bentler scaled $\chi^{2}$ $(206, n=3,987)=2,230.55 ;$ RMSEA $=0.05 ; \mathrm{GFI}=0.90 ; \mathrm{SRMR}=0.041 ; \mathrm{NNFI}=$ 0.99; CFI $=0.99 ; \mathrm{CVI}=21.75$ ] (see Fig. 1 ).

\subsection{Step (2): Testing Model 2 with Model 1}

The fit indices of Model 2 were adequate [Satorra-Bentler scaled $\chi^{2}$ (207, $n=3,987)=2,264.01 ; \mathrm{RMSEA}=0.05 ; \mathrm{GFI}=0.90 ; \mathrm{SRMR}=0.049 ; \mathrm{NNFI}=0.99$; CFI = 0.99; CVI = 21.43] (Table 4; see Fig. 2). When compared with Model 1, although Model 2's CVI was a bit lower, its fit indices were not better than those of Model 1. Therefore, Model 1 was preferred. The findings suggested that life satisfaction partially mediated the relationship of positive youth development to problem behaviour. This was used as a baseline model for further model comparison.

\subsection{Step (3): Testing Model 3 with Model 1}

The fit indices of Model 3 were also adequate [Satorra-Bentler scaled $\chi^{2}$ (206, $n=3,987)=2,230.55 ;$ RMSEA $=0.05 ;$ GFI $=0.90 ;$ SRMR $=0.041 ;$ NNFI $=0.99$; $\mathrm{CFI}=0.99$; CVI = 34.47] (Table 4; see Fig. 3), but it had a higher CVI, when compared 


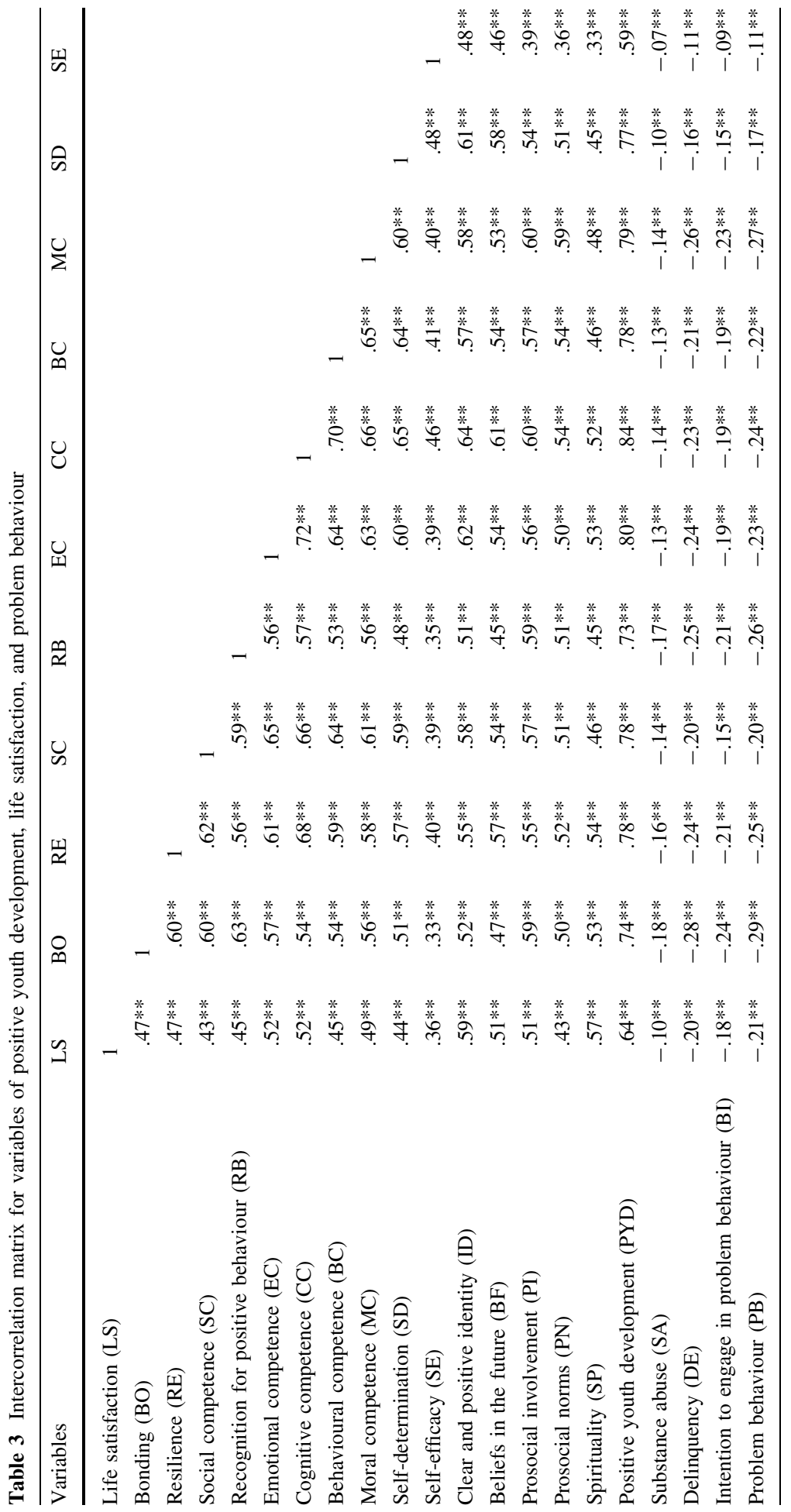




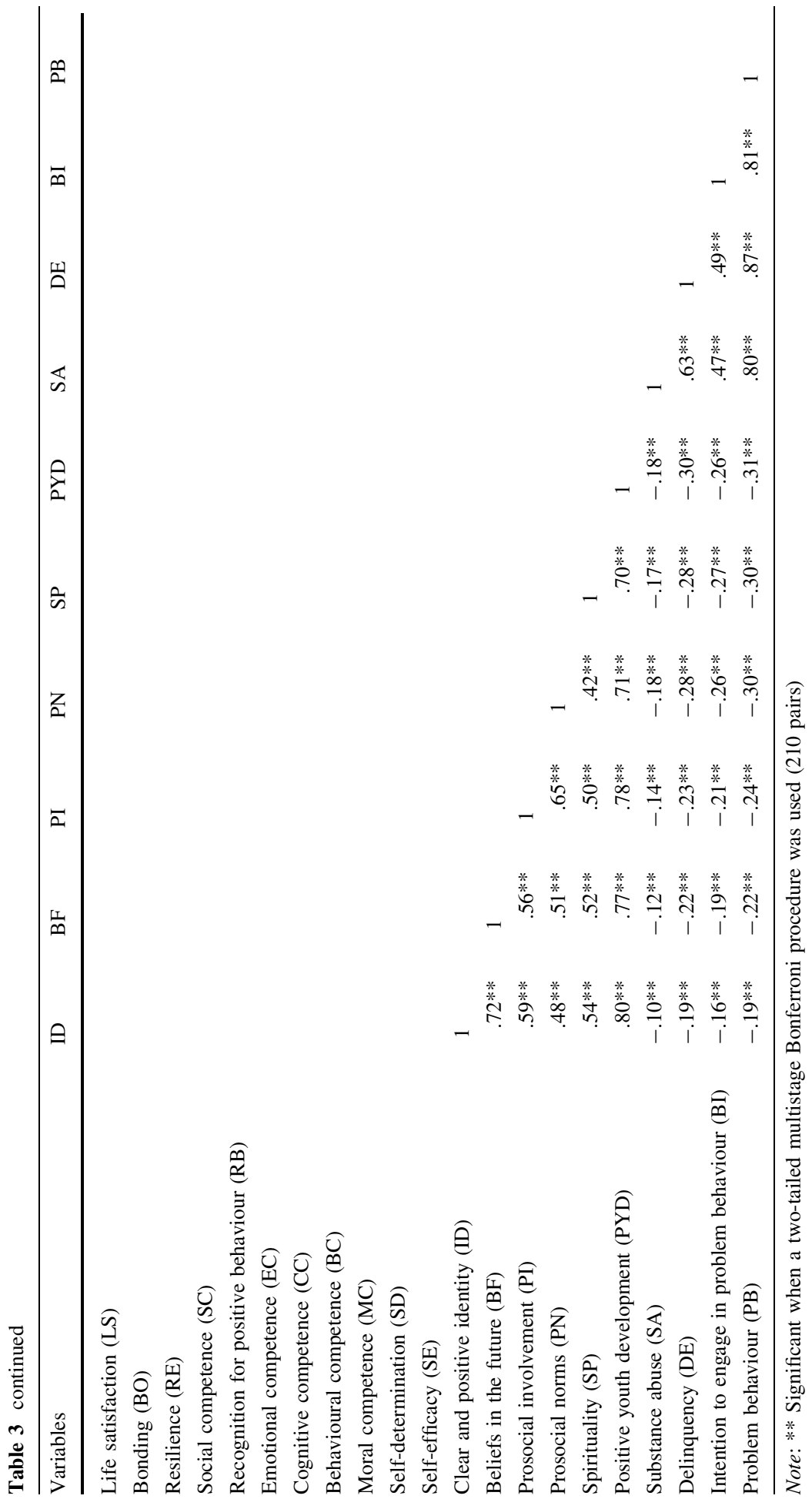


Table 4 Goodness-of-fit indices of structural models

\begin{tabular}{|c|c|c|c|c|c|c|c|c|}
\hline Structural Model & $\chi^{2}(d f)$ & $\Delta \chi^{2}(\Delta d f)$ & RMSEA & GFI & SRMR & NNFI & CFI & CVI \\
\hline (1) Model 1 & $2,230.55(206)$ & & 0.05 & 0.90 & 0.041 & 0.99 & 0.99 & 21.75 \\
\hline (2) Model 2 & $2,264.01$ (207) & & 0.05 & 0.90 & 0.049 & 0.99 & 0.99 & 21.43 \\
\hline Model 2 vs. Model 1 & & $33.51(1)^{* *}$ & & & & & & \\
\hline (3) Model 3 & $2,230.55$ (206) & & 0.05 & 0.90 & 0.041 & 0.99 & 0.99 & 34.47 \\
\hline Model 3 vs. Model 1 & & $0(0)$ & & & & & & \\
\hline (4) Model 4 & $2,275.99(206)$ & & 0.05 & 0.89 & 0.20 & 0.99 & 0.99 & 1.40 \\
\hline Model 4 vs. Model 1 & & $45.44(0)^{* *}$ & & & & & & \\
\hline (5) Model 5 & $2,263.09$ (206) & & 0.05 & 0.89 & 0.19 & 0.99 & 0.99 & 1.40 \\
\hline Model 5 vs. Model 1 & & $32.54(0)^{* *}$ & & & & & & \\
\hline (6) Model 6 & $2,214.19$ (206) & & 0.05 & 0.90 & 0.044 & 0.99 & 0.99 & 21.88 \\
\hline Model 6 vs. Model 1 & & $16.36(0)^{* *}$ & & & & & & \\
\hline
\end{tabular}

Note: A better fitting model was judged by Satorra-Bentler scaled $\chi^{2}$, RMSEA $<0.08$, GFI, NNFI and CFI $>0.90$, SRMR $<0.05$, a low CVI value, and a significant $\chi^{2}$-difference $(* * p<0.01)$

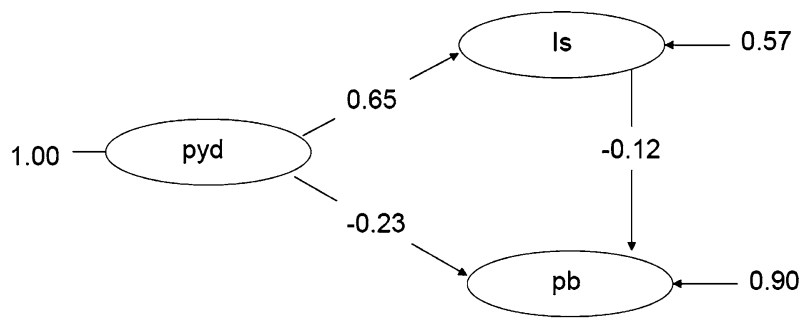

Fig. 1 Tested model 1: partial mediation model

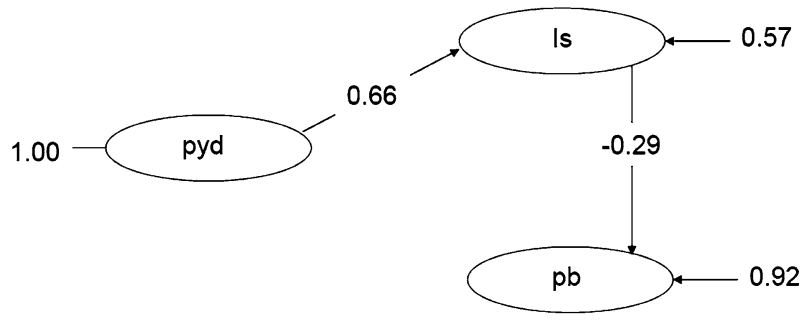

Fig. 2 Tested model 2: full mediation model

with Model 1. The model suggested that the directionality from problem behaviour to life satisfaction and positive youth development could not be easily replicated across subsamples. Therefore, Model 3 was rejected.

\subsection{Step (4): Testing Model 4 with Model 1}

When compared with Model 1, although Model 4 had a lower CVI, it had higher SatorraBentler scaled $\chi^{2}(206, n=3,987)=2,275.99$ and SRMR $=0.20$ (Table 4; see Fig. 4). It suggested that the bidirectional relationship between positive youth development and life satisfaction was not preferred. Therefore, Model 4 was rejected. 


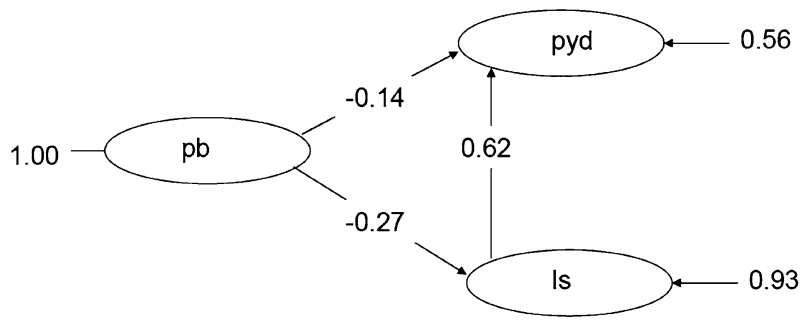

Fig. 3 Tested model 3: reverse effect model

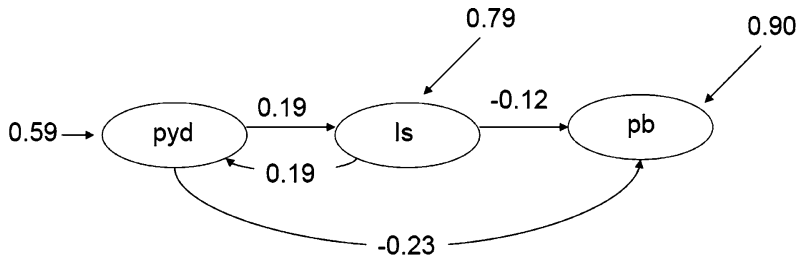

Fig. 4 Tested model 4: non-recursive model with a bidirectional path between exogenous and one endogenous variables

\subsection{Step (5): Testing Model 5 with Model 1}

When compared with Model 1, although Model 5 had a lower CVI, it had higher SatorraBentler scaled $\chi^{2}(206, n=3,987)=2,263.09$ and SRMR $=0.19$ (Table 4; see Fig. 5). It suggested that the non-recursive model with two bidirectional paths was not preferred. Therefore, Model 5 was rejected.

\subsection{Step (6): Testing Model 6 with Model 1}

The fit indices of Model 6 were adequate [Satorra-Bentler scaled $\chi^{2}$ (206, $n=3,987)=2,214.19 ;$ RMSEA $=0.05 ;$ GFI $=0.90 ;$ SRMR $=0.044 ; \mathrm{NNFI}=0.99$; CFI $=0.99$; CVI $=21.88$ ] (Table 4; see Fig. 6). When compared with Model 1, although Model 6's CVI was a bit higher, its fit indices were better than those of Model 1, and it had a significant $\chi^{2}$ difference. Model 6 was preferred and accepted as the model of quality of life in the present study because it had the most optimal fit indices, although it is noteworthy that it is only slightly better than Model 1 . Moreover, the direct effects of positive youth development on both life satisfaction and problem behaviour, and the reciprocal relationship between life satisfaction and problem behaviour, have been supported by different studies (e.g., Catalano et al. 2004; Desousa et al. 2008; Fergusson and Boden

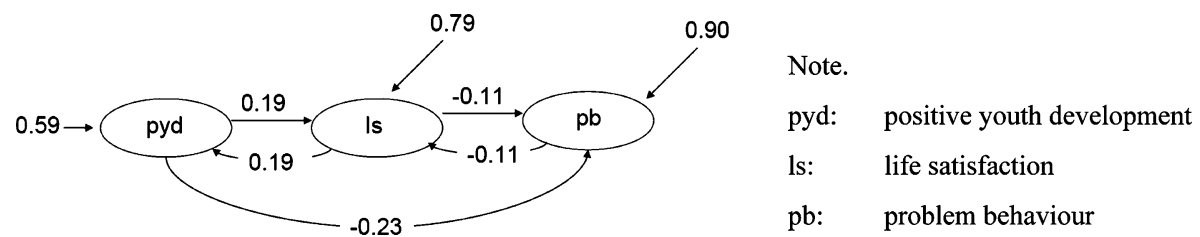

Fig. 5 Tested model 5: non-recursive model with two bidirectional paths 


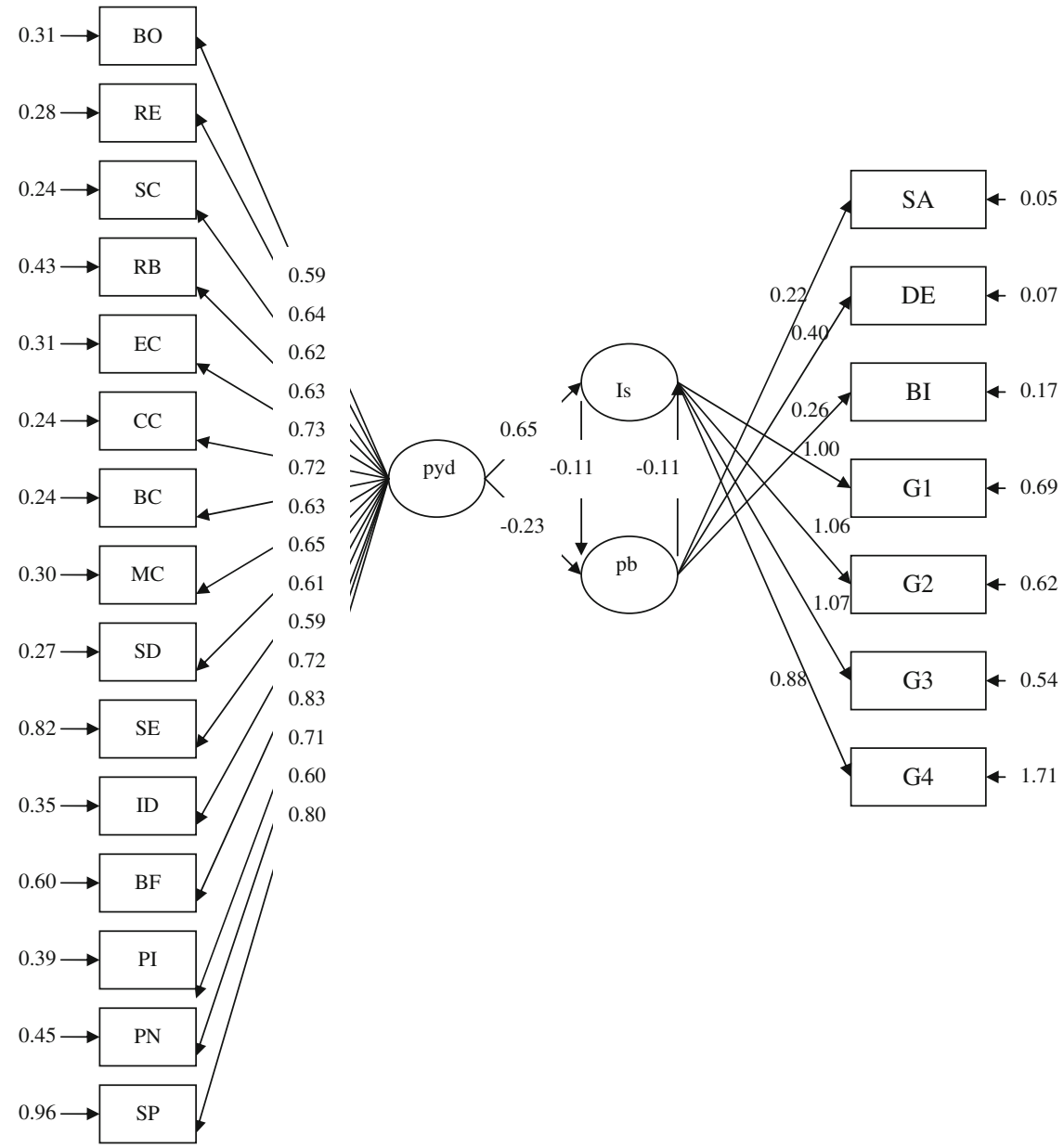

Note.

pyd: positive youth development

ls: life satisfaction

CC: cognitive competence $\mathrm{PN}$ : prosocial norms

BC: behavioural competence SP: spirituality

pb: problem behaviour

BO: bonding

$\mathrm{RE}$ resilience

MC: moral competence

SD: self-determination

SE: self-efficacy

SA: substance abuse

SC: social competence

ID: positive identity

DE:

delinquency

$\mathrm{RB}$ : recognition for positive behaviour

BF: beliefs in the future

PI: prosocial involvement

BI: intention to engage in problem

behaviour

G1-G4: 4 indicators of Life Satisfaction

EC: emotional competence

Fig. 6 Tested model 6: non-recursive model with a bidirectional path between two endogenous variables

2008). Such a non-recursive model explained $46 \%$ of the variance in life satisfaction and $12 \%$ of the variance in problem behaviour.

\section{Discussion}

The main goal of the present study was to test the different models pertinent to the relationships among positive youth development, life satisfaction, and problem behaviour 
in Chinese early adolescents. There were several unique features of this study. First, the present study is a positive response to the observation that there are few related studies in this area, particularly in the Chinese context. Second, because of the paucity of studies on adolescent quality of life (Shek et al. 2005; Shek and Lee 2007), Chinese adolescents were recruited in the present study. Third, a large sample was used in this study. Fourth, validated assessment tools were employed. Finally, latent variables analyses were performed which permit comparison of different models.

Apart from generating findings on the internal consistency of the scales of positive youth development, life satisfaction, and problem behaviour, the present study further demonstrated the validity of these constructs via confirmatory factor analyses. First, the present study affirmed that positive youth development is comprised of fifteen inter-related constructs, namely, bonding, social competence, emotional competence, cognitive competence, behavioural competence, moral competence, self-efficacy, prosocial norms, resilience, self-determination, spirituality, clear and positive identity, beliefs in the future, prosocial involvement, and recognition for positive behaviour (Catalano et al. 2004), with beliefs in the future having the strongest influence on positive youth development, followed by spirituality (Fig. 6). Therefore, future studies can compute global positive youth development, instead of using separate sub-scales, in order to have a complete picture of how positive development relates to adolescent growth and health.

Second, although the psychometric properties of the Chinese translation of the Life Satisfaction Scale had been proved (Shek 2004), the present study indicated that a scale item, "If I could live my life over, I would change almost nothing" assesses a hypothetical situation that is different from the other items, which assess present situations, e.g., "I am satisfied with my life". It is possible that a person who is dissatisfied with life does not want to change things if s/he is also helpless and hopeless. The present study showed that removal of this item could contribute to a better measurement of life satisfaction, with a better alpha value $(0.83$, mean inter-item correlation $=.56)$. Third, the present study showed that three indicators-substance abuse, delinquency, and intention to commit problem behaviour-could represent problem behaviour, with delinquency having the strongest loading (Fig. 6). Besides examining substance abuse and delinquency as indicators of problem behaviour, this study added to the literature by examining "intention to engage in problem behaviour" as another indicator. It suggests that a better measurement of problem behaviour could be obtained by assessing both past behaviour and intention for future behaviour.

Consistent with previous studies, positive youth development was positively related to life satisfaction, and both were negatively associated with problem behaviour as hypothesized. Since most existing studies have focused on bonding, social competence, emotional competence, behavioural competence, prosocial behaviour, and spirituality (e.g., Ciarrochi et al. 2003; Laudet and White 2008; Paxton et al. 2006), this study demonstrated that other positive youth development constructs, including resilience and beliefs in the future, also have significant correlations with life satisfaction. In particular, adolescents having more positive identity were more likely to have higher life satisfaction. Furthermore, problem behaviour was found to have weak, yet significant, correlation with positive youth development and life satisfaction. Interestingly, we found that adolescents are less likely to be involved in problem behaviour when they are more satisfied with life, have strong relationship with healthy adults and peers (i.e., bonding), have a sense of purpose and meaning in life (i.e., spirituality), and have clear standards for prosocial engagement (i.e., prosocial norms). 
Most importantly, the present study contributed to existing knowledge by proposing a predictive model (Model 6), which demonstrates that positive youth development predicts life satisfaction and problem behaviour, with life satisfaction and problem behaviour having a bidirectional relationship. It showed that early adolescents having poor positive development have lower life satisfaction and higher levels of substance abuse, delinquency, and intention to engage in problem behaviour. These unidirectional paths from positive youth development to life satisfaction and problem behaviour were in line with Western literature on resilience and positive youth development (e.g., Catalano et al. 2004). Since existing local studies have mainly looked at family factors (bonding) and selfconcept (identity) as determinants of life satisfaction (e.g., Chan 2007; Leung and Zhang 2000), the present study contributed by underscoring the contribution of positive youth development to adolescent life satisfaction. As positive youth development directly affects adolescents' behaviour and appraisal of life, the present findings suggest that promoting positive youth development is of paramount importance in enabling satisfaction with life and mitigating risk-taking behaviour among early adolescents. Furthermore, consistent with previous literature (Fergusson and Boden 2008; Georgiades and Boyle 2007), this study highlights the relationship of life dissatisfaction and problem behaviour, with lower levels of life satisfaction encouraging adolescents to engage in problem behaviour, and vice versa. As life satisfaction is a cognitive appraisal of the quality of one's life, it is understandable that adolescents having negative appraisal of life would engage in various kinds of problem behaviour as an outlet. Nevertheless, continuous involvement in problem behaviour would also strengthen the negative evaluation of one's life, resulting in a vicious cycle between life dissatisfaction and problem behaviour. In short, the contribution of the present findings is twofold: (i) unidirectional path models may not be adequate in delineating the relationships among positive youth development, life satisfaction, and adolescent problem behaviour; and (ii) the non-recursive model demonstrates a reciprocal causation between problem behaviour and life satisfaction.

Although the full and partial mediating role of life satisfaction (Model 1 and Model 2) was not supported by the present findings, this is not to say that the mediating role of life satisfaction should be denied-these models still showed adequate fit indices, but both models were slightly poorer when compared with Model 6. Also, the mediating effects of life satisfaction on problem behaviour are supported by Western studies in which stressful life events and parenting were treated as exogenous variables (McKnight et al. 2002; Suldo and Huebner 2004). As the present study used positive youth development as an antecedent variable, the mediating effect of life satisfaction on problem behaviour might not be prominent. In addition, this cross-sectional study did not support the reverse impact of problem behaviour on life satisfaction and positive youth development (Model 3) or that of life satisfaction on positive youth development proposed by the researchers (e.g., Meyers and Meyers 2003), and thus further demonstrated the directionality from positive youth development to life satisfaction and problem behaviour. Furthermore, this study did not support bidirectional relationships between positive youth development and life satisfaction or between positive youth development and problem behaviour (Model 4 and Model 5 ), which were logically deduced from the literature. In sum, the structural equation modelling analyses and model comparisons indicated that positive youth development was a strong exogenous variable having predictive contributions to life satisfaction and problem behaviour, with the latter two endogenous variables reciprocally related. Selection of this non-recursive model as the final model was not arbitrary. Adoption of the model was based on both the theoretical meaningfulness of the model and fit indices. However, as 
other competing models were only slightly inferior, it is necessary to replicate the present findings in the future.

There are several limitations of the present study. First, although the present model was based on a large sample collected in the Hong Kong Chinese context, the generalizability and replicability of the preferred model should be further examined. Second, causal inferences based on this cross-sectional study should proceed with caution. As the present study was based on Wave 1 data of a longitudinal study, future studies utilizing the data from several waves is necessary to validate the directionality of the variables in the model. Third, as there are certain percentages of unexplained variance in the model, it indicates that other potential variables should be included in the model to give a better prediction. Nevertheless, the amount of variance explained could not be regarded as low. Fourth, as the data were collected by students' self-reporting, the effects of social desirability and self-serving biases should be taken into consideration. Despite these limitations, the present study demonstrates that positive youth development plays an important role in the quality of life of Chinese adolescents. The present findings represent an important advance in the literature on positive youth development, particularly in the Chinese context.

Acknowledgment The preparation for this paper and the Project P.A.T.H.S. were financially supported by The Hong Kong Jockey Club Charities Trust.

Open Access This article is distributed under the terms of the Creative Commons Attribution Noncommercial License which permits any noncommercial use, distribution, and reproduction in any medium, provided the original author(s) and source are credited.

\section{References}

Anderson, J. C., \& Gerbing, D. W. (1988). Structural equation modeling in practice: A review and recommended two-step approach. Psychological Bulletin, 103, 411-423.

Caprara, G. V., \& Steca, P. (2005). Self-efficacy beliefs as determinants of prosocial behavior conducive to life satisfaction across ages. Journal of Social and Clinical Psychology, 24(2), 191-217.

Catalano, R. F., Berglund, M. L., Ryan, J. A. M., Lonczak, H. S., \& Hawkins, J. D. (2004). Positive youth development in the United States: Research findings on evaluations of positive youth development programs. The Annals of the American Academy of Political and Social Science, 591, 98-124.

Chan, D. W. (2007). Positive and negative perfectionism among Chinese gifted students in Hong Kong: Their relationships to general self-efficacy and subjective well-being. Journal for the Education of the Gifted, 31(1), 77-102.

Chang, L., McBride-Chang, C., Stewart, S. M., \& Au, E. (2003). Life satisfaction, self-concept, and family relations in Chinese adolescents and children. International Journal of Behavioral Development, 27(2), $182-189$.

Child Trends (2003) Indicators of positive development conference summary. Retrieved March 1, 2005 from http://www.childtrends.org.

Ciarrochi, J., Scott, G., Deane, F. P., \& Heaven, P. C. L. (2003). Relations between social and emotional competence and mental health: A construct validation study. Personality and Individual Differences, 35, 1947-1963.

Damon, W. (2004). What is positive youth development? Annals of the American Academy of Political and Social Science, 591, 13-24.

Desousa, C., Murphy, S., Roberts, C., \& Anderson, L. (2008). School policies and binge drinking behaviours of school-aged children in Wales-A multilevel analysis. Health Education Research, 23(2), 259-271.

Diener, E., Emmons, R. A., Larsen, R. J., \& Griffin, S. (1985). The satisfaction with life scale. Journal of Personality Assessment, 49, 71-75.

Diener, E., Suh, E. M., Lucas, R. E., \& Smith, H. L. (1999). Subjective well-being: Three decades of progress. Psychological Bulletin, 125, 276-302.

Fergusson, D. M., \& Boden, J. M. (2008). Cannabis use and later life outcomes. Addiction, 103, 969-976. 
Gebauer, J. E., Riketta, M., Broemer, P., \& Maio, G. R. (2008). Pleasure and pressure based prosocial motivation: Divergent relations to subjective well-being. Journal of Research in Personality, 42, 399420.

Georgiades, K., \& Boyle, M. H. (2007). Adolescent tobacco and cannabis use: Young adult outcomes from the Ontario child health study. Journal of Child Psychology and Psychiatry, 48(7), 724-731.

Heisel, M. J., \& Flett, G. L. (2004). Purpose in life, satisfaction with life, and suicide ideation in a clinical sample. Journal of Psychopathology and Behavioral Assessment, 26(2), 127-135.

Jessor, R., Turbin, M. S., Costa, F. M., Dong, Q., Zhang, H., \& Wang, C. (2003). Adolescent problem behavior in China and the United States: A cross-national study of psychosocial protective factors. Journal of Research on Adolescence, 13(3), 329-360.

Jöreskog, K. G., \& Sörbom, D. (1999). LISREL 8: Structural equation modeling with the SIMPLIS command language. Hillsdale, NJ: Lawrence Erlbaum Associates.

Kim, H. S., \& Kim, H. S. (2008). Risks factors for suicide attempts among Korean adolescents. Child Psychiatry and Human Development, 39, 221-235.

Laudet, A. B., \& White, W. L. (2008). Recovery capital as prospective predictor of sustained recovery, life satisfaction, and stress among former poly-substance users. Substance Use and Misuse, 43, $27-54$.

Lent, R. W., Singley, D., Sheu, H. B., Gainor, K. A., Brenner, B. R., Treistman, D., et al. (2005). Social cognitive predictors of domain and life satisfaction: Exploring the theoretical precursors of subjective well-being. Journal of Consulting Psychology, 52(3), 429-442.

Leung, J. P., \& Zhang, L. W. (2000). Modelling life satisfaction of Chinese adolescents in Hong Kong. International Journal of Behavioral Development, 24, 99-104.

MacDonald, J. M., Piquero, A. R., Valois, R. F., \& Zullig, K. J. (2005). The relationship between life satisfaction, risk-taking behaviors, and youth violence. Journal of Interpersonal Violence, 20(11), 1495-1518.

McKnight, C. G., Huebner, E. S., \& Suldo, S. (2002). Relationships among stressful life events, temperament, problem behavior, and global life satisfaction in adolescents. Psychology in the Schools, 39(6), $677-687$.

Meyers, J., \& Meyers, B. (2003). Bi-directional influences between positive psychology and primary prevention. School Psychology Quarterly, 18(2), 222-229.

Park, N. (2004). The role of subjective well-being in positive youth development. The Annals of the American Academy of Political and Social Science, 591, 25-39.

Paxton, R. J., Valois, R. F., Huebner, E. S., \& Drane, J. W. (2006). Opportunity for adult bonding/ meaningful neighbourhood roles and life-satisfaction among USA middle school students. Social Indicators Research, 79, 291-312.

Piko, B. F., Luszczynska, A., Gibbons, F. X., \& Teközel, M. (2005). A culture-based study of personal and social influences of adolescent smoking. European Journal of Public Health, 15(4), 393-398.

Sam, D. L. (1998). Predicting life satisfaction among adolescents from immigrant families in Norway. Ethnicity \& Health, 3(1/2), 5-18.

Shek, D. T. L. (1998a). A longitudinal study of the relations between parent-adolescent conflict and adolescent psychological well-being. Journal of Genetic Psychology, 159(1), 53-67.

Shek, D. T. L. (1998b). A longitudinal study of the relationship between family functioning and adolescent psychological well-being. Journal of Youth Studies, 1(2), 195-209.

Shek, D. T. L. (2004). Chinese cultural beliefs about adversity: Its relationship to psychological well-being, school adjustment and problem behavior in Chinese adolescents with and without economic disadvantages. Childhood, 11, 63-80.

Shek, D. T. L. (2007). Tackling adolescent substance abuse in Hong Kong: Where we should go and should not go. TheScientificWorldJournal, 19, 2021-2030.

Shek, D. T. L., Chan, Y. K., \& Lee, P. S. N. (2005). Quality of life in the global context: A Chinese response. Social Indicators Research, 71(1), 1-10.

Shek, D. T. L., \& Lee, B. M. (2007). A comprehensive review of quality of life (QOL) research in Hong Kong. TheScientificWorldJournal, 7, 1222-1229.

Shek, D. T. L., Lee, B. M., Lee, T. Y., \& Lam, C. M. (2006a). Frequency, satisfaction and quality dimensions of perceived parent-adolescent communication among Chinese adolescents in Hong Kong. International Journal of Adolescent Medicine and Health, 18(2), 259-270.

Shek, D. T. L., \& Ma, H. K. (2006). Design of a positive youth development program in Hong Kong. International Journal of Adolescent Medicine and Health, 18(3), 315-327.

Shek, D. T. L., Siu, A. M. H., \& Lee, T. Y. (2007). The Chinese positive youth development scale: A validation study. Research on Social Work Practice, 17, 380-391. 
Shek, D. T. L., Siu, A. M. H., Lee, T. Y., Cheng, H., Tsang, S., Chui, Y. H., et al. (2006b). Development and validation of a positive youth development scale in Hong Kong. International Journal of Adolescent Medicine and Health, 18(3), 547-558.

Shek, D. T. L., Siu, A. M. H., Lee, T. Y., Cheung, C. K., \& Chung, R. (2008). Effectiveness of the tier 1 program of project P.A.T.H.S.: Objective outcome evaluation based on a randomized group trial. TheScientificWorldJournal, 8, 4-12.

Shek, D. T. L., \& Sun, R. C. F. (2009). Development, implementation and evaluation of a holistic positive youth development program: Project P.A.T.H.S. in Hong Kong. International Journal on Disability and Human Development 8(2), 107-117.

Stein, J. A., \& Newcomb, M. D. (1999). Adult outcomes of adolescent conventional and agentic orientations: A 20-year longitudinal study. The Journal of Early Adolescence, 19, 39-65.

Suldo, S. M., \& Huebner, E. S. (2004). The role of life satisfaction in the relationship between authoritative parenting dimensions and adolescent problem behavior. Social Indicators Research, 66, 165-195.

Sun, R. C. F., \& Hui, E. K. P. (2007). Psychosocial factors contributing to adolescent suicidal ideation. Journal of Youth and Adolescence, 36(6), 775-786.

Swami, V., Chamorro-Premuzic, T., Sinniah, D., Maniam, T., Kannan, K., Stanistreet, D., et al. (2007). General health mediates the relationship between loneliness, life satisfaction and depression. Social Psychiatry and Psychiatric Epidemiology, 42, 161-166.

Valois, R. F., Zullig, K. J., Huebner, E. S., \& Drane, J. W. (2001). Relationship between life satisfaction and violent behaviors among adolescents. American Journal of Health Behavior, 25(4), 353-366.

Valois, R. F., Zullig, K. J., Huebner, E. S., Kammermann, S. K., \& Drane, J. W. (2002). Association between life satisfaction and sexual risk-taking behaviors among adolescents. Journal of Child and Family Studies, 11(4), 427-440.

Vecchio, G. M., Gerbino, M., Pastorelli, C., Del Bove, G., \& Caprara, G. V. (2007). Multi-faceted selfefficacy beliefs as predictors of life satisfaction in late adolescence. Personality and Individual Differences, 43, 1807-1818.

Wong, D. S. W. (2004). School bullying and tackling strategies in Hong Kong. International Journal of Offender Therapy and Comparative Criminology, 48, 537-553.

Zullig, K. J., Vaolis, R. F., Huebner, E. S., Oeltmann, J. E., \& Drane, J. W. (2001). Relationship between perceived life satisfaction and adolescents' substance abuse. Journal of Adolescent Health, 29, 279_ 288.

Zullig, K. J., Ward, R. M., \& Horn, T. (2006). The association between perceived spirituality, religiosity, and life satisfaction: The mediating role of self-rated health. Social Indicators Research, 79, 255-274. 